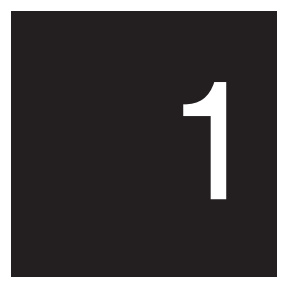

\title{
Culture and sustainable development in the Pacific
}

\section{Langi Kavaliku}

The World Decade for Cultural Development was established by the United Nations in 1988, and UNESCO was given the mandate of being the lead agency for the program. One of the major objectives of the Cultural Decade is that the 'cultural dimension' must be taken into account in the consideration of policies, formulation of plans and the implementation of development plans and programs-in our case, in the Pacific island countries.

Our task is not so much to accept the call of the United Nations or UNESCO blindly, but rather to examine critically the objective to see whether there are any real relations of interdependence between culture and sustainable development-and if so why and how. Furthermore, if interdependence is established, to examine how this finding could help us in the understanding and framing of policies, plans, and programs for the development of peoples and nation states.

\section{Culture}

Culture has many definitions, but the one I have always preferred was succinctly spelled out in the Mexico Conference in 1982. According to that formulation, culture comprises the whole complex of distinctive spiritual, intellectual and emotional features that characterise society or social groups. It includes not only the arts and letters, but also 
different modes of life, the fundamental rights of human beings, value systems, traditions and beliefs.

Culture is both an instrument for decision-making and implementation as well as the end result of those policies and of the decisions implemented. Furthermore, culture is a dynamic reality. It changes, either gradually or rapidly, over time. Indeed, it is a system that changes with each new idea, new development, each new generation and each new interaction with other cultures and/or peoples. Past cultures lend themselves to conservation. Living cultures are based on legacies of the past, the ideas of the present and the hopes for the future. In trying to understand living cultures we must also understand their legacies from the past. As Kierkegaard once wrote, 'life can only be understood backwards, but it must be lived forwards'.

\section{Sustainable development}

Development, sustainable or otherwise, is the distinctive process of a society's movement through time, whether planned or unplanned. Since the Second World War and the Marshall Plan for Europe, however, development has become so closely associated with planning that the two terms have become almost synonymous. Global macroeconomic development models were created and studied, particularly by the United Kingdom, United States, Japan, Australia and the United Nations, amongst others, and were particularly fashionable in the 1970s and 1980s. Whatever development models were designed and/or adopted, the planning and implementation of the process meant primarily economic development and economic growth-and measurements of such development were made only in quantifiable, materialistic terms. The overriding context has been, and continues to be, economic.

Into this picture the concept of the 'sustainability' of developmentthe other half of the equation we are considering in this conferencewas introduced. Sustainable development, especially as it was promulgated by the Brundland Commission, gained prominence because it added environmental and intergenerational dimensions to the original preoccupation with economic issues. The Rio Conference in 1992 gave it greater impetus. Today, in spite of the prevalence of its usage by the United Nations system as development that 'meets the needs of the present without compromising the ability of future generations to meet their needs', sustainable development is still an 
elusive term-not fully accepted by experts, policy and decisionmakers or by the public.

Like culture, sustainable development is not a steady state-system but a dynamic one. Sustainability-whether of culture or developmentchanges form and levels with time and the use of resources available. As industrial countries went through stages of agricultural, industrial and now services and information revolution, so the basis and level of their sustainability changed. In the same way sustainability has different meanings and levels of expectations as we move from a fully subsistence economy to an increasingly cash-driven economy.

I regard sustainable development as development with a working rationale-one which stipulates that the interdependence of economic, intellectual, political, environmental and cultural dimensions must be considered together in the making of policies and plans for the future of peoples and nations. In essence it is development that can be sustained not only now but also in the future, given the social and physical resources available to a nation-state and the objectives it sets for itself.

\section{Culture and sustainable development}

The interrelationship between culture and sustainable development seems to be a matter of common sense. However, even though the UN system (and especially UNESCO) is pushing for recognition of it, the UN system has not in fact been very supportive. If we study the major global conferences of the 1990s-from Rio de Janeiro to Barbados, Cairo, Beijing, Copenhagen and Harare-their plans of action were concerned with sustainable development, but there was hardly a mention, even in despatches, of culture. The various Plans of Actions from Rio to the present have had very little to say about culture, but a lot about sustainable development. Even more tellingly for us in small developing island states, the plan of action approved at the Barbados conference- - a conference designed to focus attention on the problems and needs of Small Island Developing States-culture was, I believe, mentioned only once as being an important aspect of sustainable development in the islands.

For those Pacific island countries which are members of the Commonwealth, the situation is just as confusing. Following the Barbados conference, Commonwealth leaders approved the establishment of a Ministerial Group and an Official Group to study and make recommendations to the Commonwealth Heads of 
Government Meeting (CHOGM) on how best to meet the needs and solve the problems of Small Island Developing States in the Commonwealth. Culture was hardly mentioned at all in the reports of the 1996 CHOGM.

Sustainable development was certainly fashionable, but the reports of the various meetings and the programs which were adopted showed that it was not seen to be related to culture in any meaningful way. Development to the Commonwealth group concerned economic matters, crime, security, and human resource development, law and order, health and so on, but the cultural dimension was missing.

The question therefore arises as to whether UNESCO's commitment to 'culture as an integral part of development' is due only to the fact that culture is part of UNESCO's mandate. Even though I participated in many of these global conferences I cannot answer the question why culture was not considered one of the critical issues like environment, population, energy, women and so on. I can, however, answer for UNESCO's concern. The Director-General's commitment to the importance of culture and of culture in development is fully supported by the General Conference, Executive Board, Secretariat and the National Commissions. Furthermore, and thinking positively about a seemingly negative situation, I would like to believe that because so much of the concern of these conferences, of policymakers and decision-makers are matters of culture-as defined at the beginning-that in spite of a seeming lack of concern with culture, their plans of action take matters of culture into account in any case. At the end of the day, I do not believe that any individual or group can act in a vacuum. They can only act as who they are; what they are, and what they want to be.

\section{The Pacific islands situation}

In the early 1990s, the World Bank raised concerns about the low growth rate in the Pacific Island countries compared to other small island developing states of the Caribbean and Indian oceans, where development was subject to the same sorts of constraints (small internal markets, narrow production bases, high unit costs of infrastructure, heavy dependence on external trade, vulnerability to external shocks and natural disasters and isolation from large highincome markets) while enjoying the advantages of high levels of basic subsistence, favourable climate and sustainable concessional aid flows and remittances (World Bank 1993). 
The World Bank experts called this phenomenon 'The Pacific Paradox' — simply an admission of their confusion. Indeed, the report went on to state that the Pacific Paradox did not yield to easy answers. It did, however, make suggestions on how the situation might be improved, pointing out that consideration should be given to 'the blend of customary practices and modern systems [which] has both inhibited development and helped provide some stability and social safety nets'. The implication was that 'culture' and 'customary practices' were important only as inhibitors of development and as a conservative social force. They did, however, end up recommending that 'the objective is not to impose some model derived elsewhere but to adopt new approaches'.

Since then, the growth rate in the Pacific has not shown any real improvement. The issue then for the Pacific island countries is whether or not there really is a 'Pacific Paradox'. In my view, there is no 'Pacific Paradox'. The paradox is solely in the eyes of the beholder who is blinkered against culture and sustainable development. It is not a reality.

A number of important questions were not raised such as: What is important to a Fijian, Solomon Islander, Tongan, Samoan and so on? Is it capital formation without other considerations or a balance of goods which are socially and culturally meaningful? What priority is given to meeting family and other social obligations? Is it wealth for the individual, or individual plus family, relatives and friends? What is wealth for anyway? Does it have the same meaning for a Pacific Islander as to a Westerner? Would a Tuvaluan, Ni Vanuatu or Ponapean accumulate wealth rather than help his family, relatives or neighbours?

For many experts the only remedy for the slow pace of agricultural development and therefore the growth in exports, is to change the land tenure system to allow for plantation-type agriculture. In many cases the theory may be correct, but in the Pacific island countries, one's soul and one's own identity is tied up with land and offshore resources. Do we then legislate for changing the basis of our destiny and identity? Or do we build on them? And if industrial agriculture and green revolution agriculture do not work too well in small island states, why not develop what is now called the Third Agricultural Revolution-the 'Crop Diversification Revolution' — which has long been practised throughout the Pacific.

The 'Pacific Paradox' provides a telling lesson because it shows that culture is an important aspect of development and will affect 
development and whatever we do. If we do not take culture into account and understand the interplay between it and development, we cannot move as surely as we should. If we are to participate in the global society we can only do so if we are Tongans, Papua New Guineans, I Kiribati, Fijians, Niueans and Samoans who are modern and not as modern men who happen to live in the Pacific islands. The importance of the culture and sustainability issue is that it points up the fact that what we want is the modernisation of the faa-Samoa, faka-Tonga and so on-modernisation of the Pacific Way, and not Westernisation or Asianisation or globalisation. The 'Pacific Paradox' exists only because of the influence of the concept of Westernisation.

\section{The future}

The Pacific island world is too complex for us to comprehend all its needs and problems fully, and to provide all the solutions. It is also too dynamic for any of us to assume that once problems and needs are identified and solutions provided that the solutions will last indefinitely. Neither culture nor sustainable development are steady-state phenomena. They both change, and new problems and new solutions call for continuous attention: the important thing is to understand the importance of both culture and sustainable development, as well as the relationship between the two.

There are many issues, problems and needs that we face. Gender issues, unemployment, institutions, the family and relatives, ethnic issues, hierarchical and status issues, equality, equitable distribution of income and resources, good governance, accountability, work ethics, values and social behaviour, technology, information, the media, drugs, law and order, religion, tourism, health, education, land tenure, ocean resources, regional cooperation are some of the major issues which we must address: these are the issues that challenge us in the Pacific islands as we move forward in our lives. In facing them I believe it is critical that the working inter-relationship between culture and sustainable development be understood and recognised.

In dealing with changes, the first step is to 'know thyself'. The rest of the steps are filled with the culture of the global ocean in which each of us must choose the course to take. As an example, let us take the case of women, and women and development. There are different interpretations of the position, status and role of women in Pacific island societies. Nevertheless, I believe there is one issue that we must agree 
upon and that is the equality of each and every human being. The issue facing us then, is the interpretation of what equality means. When the Secretary-General of the Tonga Women's Association came back from a conference on women in South Korea, one of her first comments was, 'Why do western women insist that we should be like them? Why do they think that their ideas are God's own and ours are backward?'

Equality in the gender issue has become almost synonymous with 'same as men'. On the other hand, I was once heavily criticised by an officer in one of our regional organisations because in a report of a meeting which I chaired, 'women' was not listed as one of the major issues.

In considering culture and sustainable development, are we talking of equality as being 'same as men' or of 'two human beings who are equal but not the same'? If it is the latter, the issue then is the equity of the complementary relationship between two beings who are equal but not the same. Either way, the cultural dimension looms large and affects both development and culture.

\section{Challenge of choice}

The lokua is a small fish that lives in reef ponds cut off from the surrounding waters during low tides, but when the tides are high, they are periodically replenished by ocean waters. For people living in the Pacific islands, the issues are much the same as those faced by the lokua: whether to be an integral part of the larger ocean or to remain in our own little ponds, nurtured mainly by our own resources, but having them replenished from time to time by the regional and global environments.

If we want to become more and more a part of the global society, how much of the sheltering walls of our ponds do we want to knock down, in order to allow for a greater flow of ocean both at low tide and high tide? Can we be ourselves in a bigger world? What is our future among the bigger fish of the world's ocean? What resources will there be to allow us to live and participate in the global society?

Questions of identity, culture, security and resources take on different dimension. Sustainability of both culture and development becomes paramount. Conversely, if each of us remains in our pond what would that mean? Could we survive?

No bystanders are allowed. The choice has to be made. The most challenging choices to be made concern cultural and environmental factors, social and physical resources. And we must face the ramifications of our past choices as well as the new ones arising from the global currents of the present. 
Can we say that sustainable development, or indeed any sort of development, has no need to take into account the cultural dimension? In this regard I am reminded of the story of the tourist who went to a restaurant in a rather remote area. The restaurant had an impressive menu listing over a hundred dishes. After the tourist had made two orders and found that the restaurant in fact had neither of them, he asked the waiter to tell him what could be provided, and the waiter told him the two dishes they had. After he had ordered one of them he asked the waiter why they had such a menu when they could only produce two dishes. The waiter told him that the menu was planned and agreed in the capital, without regard for what was available locally. They were told it was the menu restaurant owners would have if they were running proper establishments which were both profitable and sustainable.

The experts and decision-makers agree on the formula. But is this really the way it should be? Is there any other way for a developing nation with limited resources to avoid being relegated to the bottom of the class because it hasn't got all the items required by the formula to be considered a success?

The question of what to do if you have limited resources is rarely touched on in discussions of culture and sustainable development. What standard of living and quality of life should you aim for? What sort of society? Who and what do you want to be? What pathways of development should many of us consider even with our being nurtured by the ocean of the global society. Asking these questions reminds me of a statement by Perez de Cuellar to the effect that development embraces not only access to goods and services but also the opportunity to choose a full, satisfying, valuable and valued way of living together, the flowering of human existence in all forms and as a whole. The choice can also be for a different style of development, a different path based on assessed resources and different values from those of the highest income countries. Different paths of development should be informed by a recognition of how cultural factors shaped the way in which societies conceive their own future and choose the means to achieve those futures.

Jacques Delors, the former President of the European Commission, stated that all-out economic growth can no longer be viewed as the ideal way of reconciling material progress with equity, respect for human conditions and respect for natural assets. 
In fact we have choices and we face challenges that require a fundamental shift in our view on culture and sustainable development in order to be realistic in our objective and at the same time develop a life-style which each and every one will live with pride. The issue is not just the importance of culture in development but the issue of sustainability of our future in a global situation.

It is also necessary to keep in mind that both culture and sustainable development are dynamic processes. They are both instruments of change and the end results of change. What we are today is different in many ways from what we were 25 years ago and different from what our societies were 50 years ago. We should not be troubled by the lifestyle and livelihood changes all around us. We must make decisions about future directions and the goals. That is also why culture is a critical factor in development-sustainable or otherwise.

The challenge of choices will also be in development of ways and means of enlarging resources. In the same way that Israel and the Jews outside of Israel are interdependent, remittances are becoming increasingly important in the Pacific island countries and consequently the cultural dimension becomes significant. The Pacific island countries own, or have some control, over 3 million square miles of ocean and its resources. Why is it not possible for us to come together and work together in order to enlarge resources for ourselves? Is it because of cultural differences? Is it politics?

The world is rapidly reconfiguring itself into competing regional blocs, based on economic grounds. The European Union is expanding. North America now has NAFTA and the Organisation of American States. ASEAN is becoming a major player especially with the momentum of the new bloc, APEC, a reality recognised by Australia and New Zealand. This is an issue which the island states must address-sooner rather than later. The currents of the global ocean are shifting from the Atlantic to the Pacific Rim, and especially Asia. What do these shifting currents mean for us in the islands? What does it mean to be in the midst of the Pacific, yet forgotten?

I have raised these general issues because in my view they will affect us all. Do we in the islands take on these developments individually? Why is regionalism and regional cooperation a difficulty? Is it because of our cultures? Is it possible to build a regional identity to facilitate not only the development of regional cooperation but also of shared resources and allow island states, individually or together, to 
participate more fully in the global society? Perhaps our concern in islands should be more about the regional society in order for us to be better able to participate in and benefit from the global society. If we are successful, we may also give hope to youth and the population at large. The issues are social and cultural, as well as moral, political and economic. They also have intellectual dimensions, not only for the élite but also for Pacific people in general. Questions of development, regional cooperation, natural and human resources, gender issues, reaching the unreached (our youth) must also be considered by ordinary men and women. Perhaps after all there is a case for culture and sustainable development.

There is a Tongan saying, Taumulivalea, which roughly translated means that if you do not know where you come from, how can you hope to know where you are going? This proverb highlights the reasons why culture is important in any discussion of development and any hope for the future.

However, 'taking account of cultural dimensions' in sustainable development is not a panacea for all our problems. It is only a small but important part of the formula, which is all too often implied but not treated vigorously or seriously. It is a part of the process of development as well as the objective of that development. We need economic development in order to live. We need to consider the environment in order to be able to hand over with a clear conscience to future generations. We need to consider other social, political and intellectual dimensions in order to enhance our lifestyles and standards of living. We need to consider culture not only to achieve our objectives but also to achieve a quality of life befitting the integrity of each and all of us as human beings who are also Pacific islanders, as well as Fijians, Samoans, Nauruans and so on.

As the Director-General of UNESCO stated that we must be able to assimilate the best of the past in order to be able to better share the future with the help of a judicious application of knowledge. Cultural development is an instrument and an objective of sustainable development.

\section{Reference}

World Bank, 1993. Pacific Island Economies: toward efficient and sustainable growth, The World Bank, Washington, DC. 